\title{
Using orthogonal experiment design to optimized powder metallurgy repair process
}

\author{
Jie Zhang ${ }^{1,2 a}$, Yuchun Zhai ${ }^{2, b}$ and Maocai Wang ${ }^{3, c}$ \\ ${ }^{1}$ Department of Biological Engineering, Liaoning Economic Management Cadre Institute, China \\ ${ }^{2}$ Metallurgy College, Northeastern University, China \\ ${ }^{3}$ State Key Laboratory for Corrosion and Protection, Institute of Metal Research, Chinese Academy \\ of Sciences, China \\ axinlinghudie@163.com, bhaiyc@smm.neu.edu.cn, wmc@imr.ac.cn
}

Keywords: orthogonal experiment design, LPM, powder metallurgy repair, process parameters, intuitive analysis, variance analysis

Abstract. The orthogonal experiment design method was applied to powder metallurgy repair process parameters optimization. With orthogonal design combined with weighted comprehensive evaluation method to influence repair effect of multiple objective indicators comprehensive score, and then through the intuitive analysis and variance analysis determine the optimal collocation of factors and levels, and experiment validation. The results show that the influencing factors on the quality of the final repair order is sintering temperature $>\mathrm{B} 1 \%>$ the binder amount added $>$ ball milling time. The optimal process parameters are with $10 \% \mathrm{~B} 1$, ball mill for $10 \mathrm{~min}$, adding $7 \%$ adhesives, sintered under $1200^{\circ} \mathrm{C}$. Using optimized process repair quality are in conformity with theoretical analysis results

\section{Introduction}

Liburdi Powder Metallurgy (LPM ${ }^{\mathrm{TM}}$ ) employs advanced metallurgy to achieve high strength repair joints, in conjunction with reliable mechanical preparation of the surfaces. Damaged areas are first removed by grinding similar to preparation for welding. Then new LPM $^{\mathrm{TM}}$ material in putty or tape form is applied to fill the area; the part is then processed through specialized vacuum heat treatments and machined or blended to the final dimensions ${ }^{[1]}$. The process conditions influence on the final quality of repair exists many uncertain factors, good experimental design method in a certain extent can reduce the blindness of trial and error, can get the best process combination with less test times. $\mathrm{LPM}^{\mathrm{TM}}$ method has been widely used in engine turbine static blade remanufacturing such as G.E Frame3, $6 \mathrm{~B}$, 7 B and LM1600; Siemns Westinghouse company W191, W251, B8 and B10, B12, W501D; Rolls Royce company T56, RB211, TB5400, DJ270 engine turbine static blade ${ }^{[2,3]}$.

In China, gas turbine parts repair technology of hot end, although there is a certain development ${ }^{[4]}$, but the basic research and application level also has the very big disparity compared with western developed countries. Due to assess the final repair a lot of quality indicators, the optimization of only one value are difficult to obtain the optimal process scheme. Therefore, in this paper, orthogonal experiment combined with weighted comprehensive evaluation method was studied, according to the target value of important degree of the influence of interface connection situation, etc, weighted composite score, and then through the analysis of the poor, analysis of variance to determine the factors and the level of various factors on the influence degree of the comprehensive value, find out a set of optimal process parameters, test and verify.

\section{Powder metallurgy repair process parameters optimization design method}

Orthogonal experimental design There are many factors that can affect the repair quality, such as sintering temperature, sintering time, alloy substrate condition and gap size of injury, repair material selection, etc. ${ }^{[5]}$. In this paper, orthogonal experiment were carried out with four factors selected, respectively, sintering temperature(T), activation sintering material content, powder mixed time (ball 
mill time t), the binder ratio(M\%). Choose four factors three levels of design table L9 (3) 4 orthogonal experiments, with sintered density and interface connection as an index for consideration. Analysis of the goal is to determine the final density of sintered body (Y1) and interface connection (Y2) comprehensive value of the two indicators. Y2 is a numerical result, which can be described in the form of a percentage and factor levels as shown in table 1.

Table 1 Factor and levels schedule table

\begin{tabular}{|c|c|c|c|c|}
\hline \multirow{2}{*}{ level factor } & 1 & 2 & 3 & 4 \\
\cline { 2 - 5 } & $\mathrm{B} 1 \% /($ mass $) \%$ & $\mathrm{~T} /{ }^{\circ} \mathrm{C}$ & $\mathrm{t} / \mathrm{min}$ & $\mathrm{M} \% /(\mathrm{mass}) \%$ \\
\hline Level 1 & 10 & 1200 & 10 & 10 \\
\hline Level 2 & 5 & 1180 & 30 & 7 \\
\hline Level 3 & 1 & 1150 & 60 & 5 \\
\hline
\end{tabular}

Experiment materials and method. IN738 superalloy was used to be repaired as base material, and IN738 powder ( -325 mesh) as the matrix powder, mixing different proportion of B1 activated sintering powder, respectively, by using high-energy ball mill mixing $10 \mathrm{~min}, 30 \mathrm{~min}$ and $60 \mathrm{~min}$. And then, respectively, the samples mixing $5 \%, 7 \%$ or $10 \%$ adhesives, were made into nine groups of test samples as the table above, and each group of three samples are used to calculate the average. After nine pairs of trials, the samples were tested on METTLER TOLEDO AG285, Max81g / $210 \mathrm{~g}$ density test device (Archimedes principle), and Optical microscope and scanning electron microscope (SEM) to measure the density of the sample and judge the quality of interface connection.

Data proceeding. Simulation test of the selected indicators on final repair quality target each have emphasize particularly on, therefore, the weighted scoring method is adopted for weights allocation ${ }^{[6]}$. Weights allocation according to the result of orthogonal experiment analysis and index on the quality of the final repair degree by the centesimal system weighted.

First of all the indicators dimensionless, be calculated According to the formula (1) (2)

$$
\begin{gathered}
Y_{j i}^{\prime}=\left(100 / R_{i}\right)\left[Y_{j i}-\left(Y_{\text {min }}\right)_{i}\right] \\
R_{i}=\left(Y_{\text {max }}\right)_{i}-\left(Y_{\text {min }}\right)_{i}
\end{gathered}
$$

In the formula: $Y_{j i}$ the $j$ test item $i$ observation; $\left(Y_{\max }\right)_{i}$ the max of $i$ indicator; $\left(Y_{\min }\right)_{i}$ the min of $i$ indicator; $R i$ the test indexes of poor; $Y_{j i}^{\prime}$ the score value of $j$ test $i$ indicator. Density of sintered body and weights of interface connection were $\mathrm{b} 1=0.6$, respectively, $\mathrm{b} 2=0.4 ; Y j$ weighted composite score value computation formula is as follows:

$$
Y_{j}=b_{1} Y_{j 1}^{\prime}+b_{2} Y_{j 2}^{\prime}=\sum_{i=1}^{2} b_{i} Y_{j i}^{\prime}
$$

In the formula: $j$ test number; $i$ Objective indicators; $i$ value 1 and $2 ; Y j$ the weighted score of $i$ test item.

\section{Results analysis of orthogonal test}

Intuitive analysis. After nine groups of experiments, the results as shown in table2. Data in the table also shows the various index of the comprehensive score and weighted score. In order to get the factors and indicators, the relationship between seeking level the best collocation of various factors, intuitive analysis first, calculated for each factor in each level of average and poor. The greater the poor show that the factors of influence degree of the bigger; the smaller the poor, that influence the less significant. Poor test of each factors in the analysis of the results are shown in table 3. Level influence trend is shown in figure 1. 
Table2. The orthogonal experiment results and score

\begin{tabular}{|c|c|c|c|c|c|c|c|c|c|}
\hline & $\mathrm{A}$ & $\mathrm{B}$ & $\mathrm{C}$ & $\mathrm{D}$ & \multicolumn{5}{|c|}{ results } \\
\hline factors & $\mathrm{B} 1 / \%$ & $\mathrm{~T} /{ }^{\circ} \mathrm{C}$ & $\mathrm{t} / \mathrm{min}$ & $\mathrm{M} / \%$ & $\mathrm{Y}_{1} / \mathrm{g} \cdot \mathrm{cm}^{-3}$ & $\mathrm{Y}_{2} \%$ & $\mathrm{Y}_{1}$ & $\mathrm{Y}_{2}$ & weighted score $\mathrm{Y}_{\mathrm{j}}$ \\
\hline Exp-1 & 1 & 1 & 1 & 1 & 7.616 & 95 & 100 & 90.91 & 96.36 \\
\hline Exp 2 & 1 & 2 & 2 & 2 & 6.879 & 96 & 69.17 & 95.45 & 79.68 \\
\hline Exp 3 & 1 & 3 & 3 & 3 & 6.24 & 85 & 42.45 & 45.45 & 43.65 \\
\hline Exp 4 & 2 & 1 & 2 & 3 & 6.645 & 93 & 59.39 & 81.82 & 68.36 \\
\hline Exp 5 & 2 & 2 & 3 & 1 & 5.431 & 80 & 8.62 & 22.73 & 14.26 \\
\hline $\operatorname{Exp} 6$ & 2 & 3 & 1 & 2 & 5.225 & 75 & 0 & 0 & 0 \\
\hline $\operatorname{Exp} 7$ & 3 & 1 & 3 & 2 & 7.532 & 94 & 96.48 & 86.36 & 92.43 \\
\hline $\operatorname{Exp} 8$ & 3 & 2 & 1 & 3 & 7.437 & 97 & 92.51 & 100 & 95.51 \\
\hline $\operatorname{Exp} 9$ & 3 & 3 & 2 & 1 & 6.043 & 80 & 34.21 & 22.73 & 29.62 \\
\hline
\end{tabular}

Table. 3 range analysis results

\begin{tabular}{|c|c|c|c|c|}
\hline \multirow{2}{*}{ the average } & \multicolumn{4}{|c|}{ factors } \\
\cline { 2 - 5 } & $\mathrm{A}$ & $\mathrm{B}$ & $\mathrm{C}$ & $\mathrm{D}$ \\
\hline average 1 & 73.231 & 85.718 & 63.958 & 46.748 \\
\hline average 2 & 27.54 & 63.15 & 59.221 & 57.37 \\
\hline average 3 & 72.52 & 24.423 & 50.113 & 69.173 \\
\hline range & 45.691 & 61.295 & 13.845 & 22.425 \\
\hline
\end{tabular}

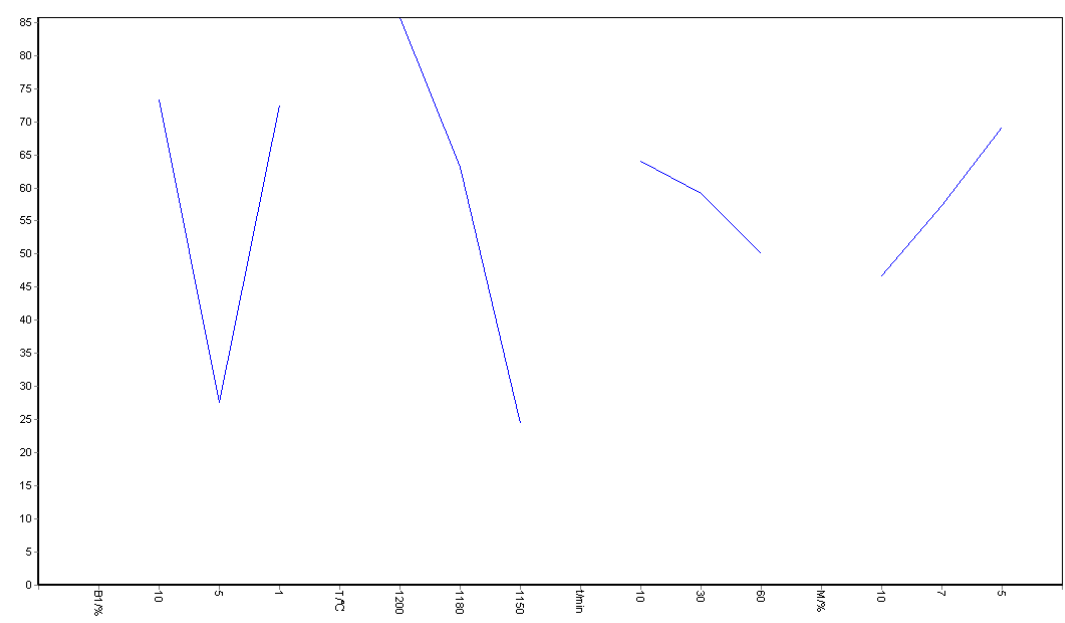

Fig. 1 level effects trend of orthogonal test

The results show that the sintering temperature of poor is the largest 61.295 , followed by B1 content 45.691, for the content of the binder and the ball grinding time after. The larger the range is, the greater the effect of the result is, and the order of the factors affecting the quality of repair is the order of the factors, $B>A>D>C$. From the level of the influence of the level of Figure 1, we can know that the overall score of B1 is higher when the amount is $10 \%$, the second is to add $1 \%$, and the last is to add $5 \%$;Therefore, combined with the poor level of analysis and influence the trend as a result, it is concluded that the optimal combination for A1B1C1D3 process.

Range analysis. Range analysis has certain limitations, cannot estimate test process and test results of measurement error exists in ${ }^{[7]}$, so generally make up for the inadequacy of poor analysis with the method of variance analysis. Analysis of variance $(\mathrm{P}<0.05)$ results is listed in table 3. 
Tab. 4 variance analysis results

\begin{tabular}{|c|c|c|c|c|c|}
\hline factors & quadratic sum & freedom & F ratio & $F_{1}$ critical value & significant \\
\hline A & 4111.404 & 2 & 13.841 & 19.000 & \\
\hline B & 5766.105 & 2 & 19.411 & 19.000 & $*$ \\
\hline C & 297.055 & 2 & 1.000 & 19.000 & \\
\hline D & 755.041 & 2 & 2.542 & 19.00 & \\
\hline deviation & 297.06 & 2 & & & \\
\hline
\end{tabular}

The results from the analysis of variance show that the sintering temperature of $\mathrm{F}$ ratio 19.411 is greater than the critical value F 19.000, so the effect of sintering temperature on the final target is the largest, as the significant factors, and B1 content as the secondary factors, and ball mill time and the binder ratio no significant influences on the targets of the end.

According to the views of variance analysis ${ }^{[7]}$, to choose the best level we should be according to the significant factors, while other minor factors that affected the result could be selected according to the actual need. As a result, in this article the optimal collocation of a variety of factors is A1B1C1D3, namely the optimal process was: adding $10 \% \mathrm{~B} 1,10$ minutes of ball mill, and add $5 \%$ binder in $1200^{\circ} \mathrm{C}$ sintering.

Validation experiment. By the results of orthogonal experiment, we made a test for validation with $10 \% \mathrm{~B} 1$ added, ball mill for $10 \mathrm{~min}$, and $7 \%$ binder at $1200{ }^{\circ} \mathrm{C}$ sintering. The test results show that the density of sintered body is $7.685 \mathrm{~g} \cdot \mathrm{cm}^{-3}$. While interface connection quality has been analyzed by Scanning electron microscopy and the results were shown in figure 3. It was shown that the sintered interface was metallurgical bonding with no obvious defects (see figure 3 ). Weighted composite score for the test was 99.22 compared in table 2 rating data for the highest. So we know from the above analysis validation process parameters are relatively optimal, consistent with the above conclusion.
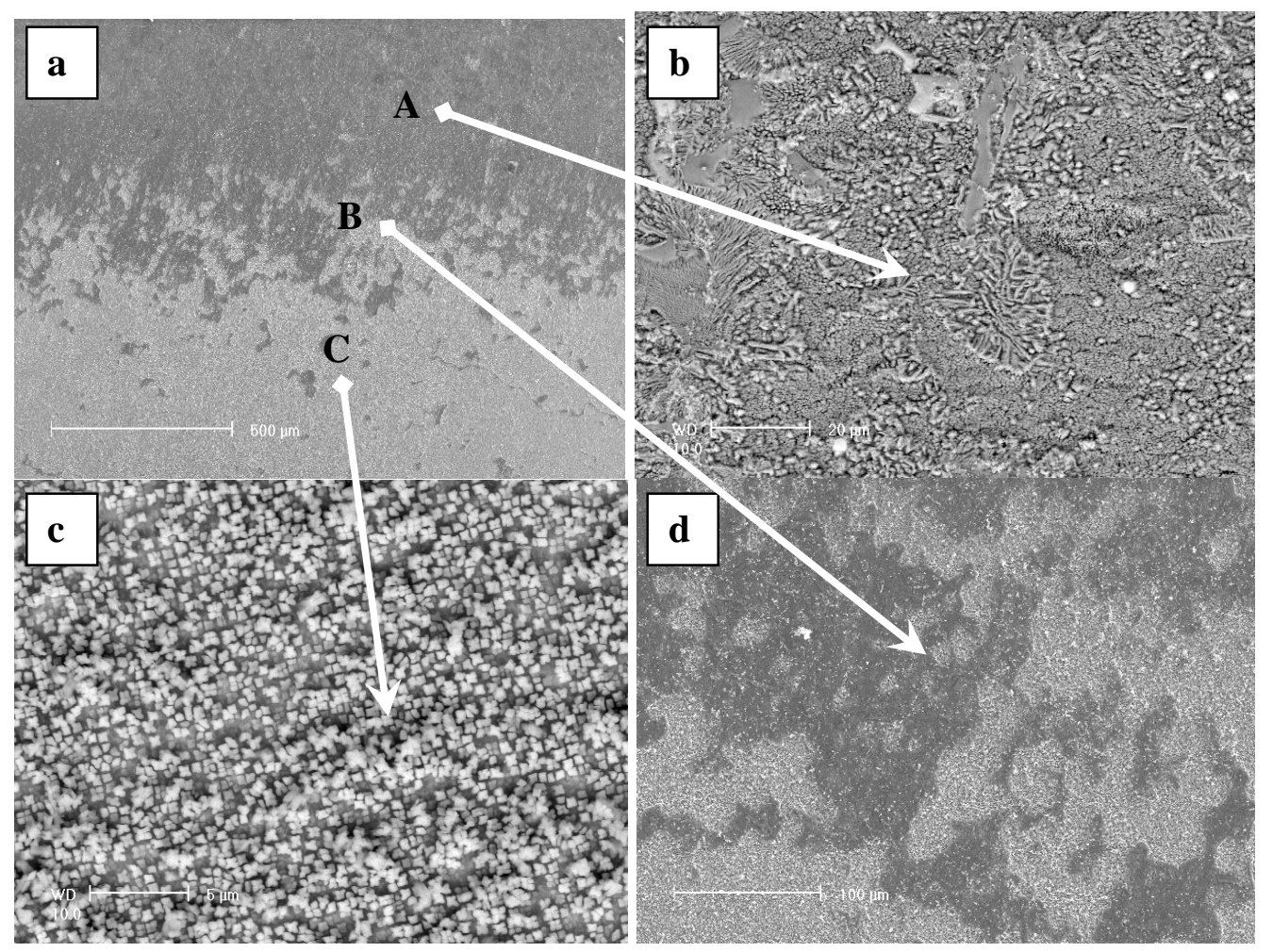

Fig. 3 SEM images on connection interface of the validation test sample

\section{Results discussion}

The orthogonal experiment results show that the temperature is significant influencing factors and the activation sintering powder B1 content for the secondary factors. It is mainly because of sintering is the 
powder when heated to high temperature combination with each other together, sintering rate constant $\mathrm{K}$ in line with the Arrhenius formula:

$$
K=A \exp (-Q / R T)
$$

$\mathrm{A}$ is including reaction atom collision "frequency factor" constant; $\mathrm{Q}$ for sintering process activation energy; $\mathrm{T}$ as the sintering temperature. Therefore, the higher the temperature, the better for sintering; And activated sintering powder added can lower the activation energy of the sintering process, and improve the reaction between atomic collision frequency, influence on sintering is also very obvious. In conclusion, the test results are consistent with theoretical analysis.

\section{Conclusions}

(1) The four factors influencing the powder metallurgy repair process influence size order: sintering temperature $>$ activation powder content $>$ add the binder quantity $>$ ball grinding time;

(2) The optimal process parameters for adding 10\% B1, ball mill for $10 \mathrm{~min}$, adding $7 \%$ adhesives, sintered under $1200{ }^{\circ} \mathrm{C}$.

(3) Verification test shows that under the optimizing of process parameters to repair defect, high temperature alloy sintered body density is higher, connection interface for metallurgical combination;

\section{Acknowledgements}

This work was financially supported by the Natural Science Foundation (50671116)

\section{References}

[1] J. Liburdi, P. Lowden and K. Ellison, U.S. Patent 5,156, 321. (1992)

[2] K. A. Ellison, J. Liburdi and J. T. Stover: The Minerals, Metals \& Materials Society, (1996), p. 763

[3] R. Sparling and J. Liburdi: in Proceedings of the Sixth International Charles Parsons Turbine Conference, Dublin, Ireland, UK, (2003), p. 987

[4] M. C. Wang, W. T. Wu: Gas Turbine Technology, Vol. 14(4) (2001), p. 53

[5] Y. J. Xie,M. C. Wang, M. S. Wang: China Surface Engineering, vol. 23(5) (2010), p.1

[6] D. Y. Liu: Medicine mathematical statistic (People's Medical Publishing House, Beijing 1999)

[7] S. H. Zheng, S. H. Jiang: Experimental design and data processing (China building industry press, Beijing 2004) 